International Journal of Distributed and Parallel Systems (IJDPS) Vol.3, No.4, July 2012

\title{
MOBILE LEARNING (M-LEARNING) AND EDUCATIONAL ENVIRONMENTS
}

\author{
Mohamed Sarrab \\ Communication and Information Research \\ Center, Sultan Qaboos University, \\ Al-Khodh Muscat 123, \\ Sultanate of Oman \\ sarrabesqu.edu.om
}

\author{
Laila Elgamel, Hamza Aldabbas \\ Software Technology Research Laboratory \\ De Montfort University, \\ LE1 9BH, \\ Leicester, UK \\ $\{$ laila, hamza\} @dmu.ac.uk
}

\begin{abstract}
Mobile devices show a dramatic departure from old-fashion of computing platforms as they no more represent a static or fixed notion of context, where changes are small, absent, or predictable. With this dramatic departure, the expansion and continued evolution of modern mobile devices an opportunity has arisen for much more comprehensive integration of these modern devices into educational environments. Mobile learning is a new research area, that has become an emerging tool for our education system. The mobile learning can be used to enhance the overall learning experience of our students and teachers. This paper discusses the background of mobile learning and how it can be used to enhance the whole eLearning system. The paper presents the M-learning approach as the next generation of eLearning, whereas the next generation of the learning systems will provide easy access and widely available to all who wish to be part of it. The paper also highlights the benefits and future challenges of mobile learning in our educational environments.
\end{abstract}

\section{KEYWORDS}

Mobile Learning, eLearning, Educational Environments.

\section{INTRODUCTION}

The term mobile refers to possibility of taking place in multiple locations, across multiple times, and addressing multiple content areas using either static or portable equipment's such as wireless laptops, Personal Digital Assistants (PDAs) and smart phones. The fastest developing and rising computing platform with an estimated 1.6 billion mobile device users by 2013 is smart phones, mobile devices and PDAs [1]. Different kinds of educational usages have been reported, such as language teaching using short messages [12], vocabulary and practice questions [13], and many experiential learning situation and informal problem-solving. As Internet and computers become very important educational tools, the modern technologies become more effective, portable and easy to use. Mobile devices are much more reasonably priced (phones and PDAs) than desktop computers, and have a less expensive method of Internet access. Currently, the tablet PCs allows mobile internet access with equal or more functionality than desktop computers. The term mobile learning or in short M-Learning refers to the use of mobile and handheld IT devices, such as mobile telephones, laptops, PDAs and tablet PC technologies, in training, learning and teaching. The mobile learning can be considered as the third wave of learning with mainframe and, desktop computers as the first and second waves.

One of the mobile technologies strongest argument is their availability, where mobile devices can be accessed much easier than desktops. Somewhat surprisingly, despite a large amount of 
International Journal of Distributed and Parallel Systems (IJDPS) Vol.3, No.4, July 2012

installed desktop computers over the world, students are enjoying a little access to those desktop computers. For example, universities provide many computer facilities, and indeed they have many labs densely packed with desktop computers. But, most of these computer labs are located for underground students in a remote corner of the campus and they are usually unavailable for self-access due to the fact that they are almost constantly reserved for teaching classes.

At home, a huge number of desktop computers are distribute between families, but in fact it is usually shared between family members. Mobile devices outnumber desktop computers 5 to 1 [23]. Moreover, many students spend most of their daytime away from home. In fact most of students spend only a very few hours with computers each week. This lack of exposure and the complexity of desktop computers means that many of our students are not very comfortable with computers. In contrast, most of university's students constantly carry web capable mobile devices. Students extensively use their mobile devices to send short email messages and view huge number of web pages each week, during the waiting time between classes [24]. In future students should be regularly allow to utilize some of this time, and enable the use of mobile technology outside the classroom. Nowadays, students are very rarely asked to use their mobile devices for school work. In fact, most of universities explicitly prohibits the use of mobile devices inside classrooms and students are very rarely use the web browser in their mobile devices to search or look up information during lectures and classroom exercises. Some students may use their mobile devices in foreign language classes for look up words in bilingual dictionaries either built in or web based dictionaries. Other students may use their mobile cameras to photograph blackboards, PowerPoint displays or any other important documents. Therefore, mobile devices can be an effective educational platform, due to the fact that mobile devices are easily accessible by students and provide adequate support for standard Internet technologies. Using modern methods and techniques integrated in M-learning, help in making the learning of our student more interesting, more interactive, widely available and flexible. Mlearning is cost-efficient that helps students to learn more without traditional restrictions. Furthermore, the possibility to integrate M-learning systems into existing E-learning systems [25] makes it easy to stay in touch with the newest advances made in teaching research. Mobile devices are expected to be a part of every class and activity both inside and outside lecture classrooms, rather than being limited to a few assigned functions in rarely visited computer labs.

\section{LITERATURE REVIEW}

Despite a large amount of mobile phone technology development in mobile phones more than 20 years, there is not development can be seen comparing with what can be seen in internet innovations. Even there is a wide mobile technology market, very few trivial applications developed over the past 20 years. Several research has been done on M-learning environment including requirements design [26], architecture [27], M-learning model [28] and current trend [29]. Also there are some applications in the market that enable teachers to manage their online quizzes and monitor the their students' progress online, such as Alykko [18]. Alykko is an intelligent mobile tutoring tool for teachers that supports interaction and educating dialogue using mobile technologies. It helps teachers in managing their tutors activities using web and mobile technologies. It also supports communications between students and their teachers using either the system on mobile devices or personal computers. Active campus [31] is a contextaware organizer that supports some classroom activities. The provided activities include asking the instructor online anonymous question for students who are shying or having online quizzes in classrooms made by the instructor. The Active campus was successfully adopted to the real world but the main drawback is that some students do not like to use it and they said that they do not have any questions to ask the instructor. A context-aware mobile and collaborative learning scenario [32] is a context-aware mobile application for university that supports many universities campus requirements such as in the beginning of each session, The attendance list is filled automatically during sessions, lecture materials are loaded in a student hand-held device. 
International Journal of Distributed and Parallel Systems (IJDPS) Vol.3, No.4, July 2012

Absent students will be informed via SMS. POODLE[33] is a course management system for mobile phones which is a redesigning of MOODLE[5], for being suitable for hand-held devices and compatible with wireless networks. This course manager provides many features such as online and offline text assignment, designing quizzes, course files, survey tools, chats, online question in class and library. Saipunidzam et. Al [30] provided a new approach of M-learning environment with mobile graph for tracking the students' progress and performance. They argue that the purpose of this system is not to replace traditional classrooms but to complement the learning process in Malaysian schools. Since the development of mobile application is not yet as matured as desktop or personal computer application development, which may take some time to establish and provide a well-accepted standards [22]. Therefore, there is no standard developed for M-learning yet. But the existing E-learning standards and models can be used to develop M-learning applications. With the rapid increasing in the development of wireless technology, learners are exposed to a new learning and educational experience, what is called mobile learning or m-Learning. The experts in this field have offered different definitions for this form of learning. Such as that the M-Learning is e-learning through mobile computational devices [14]. A project group in Norway in 2001 have defined M-Learning as a new learning mechanism using mobile devices because of Geo-spatial mobility and the increasing demand for flexible learning [15]. In 2002 Chabra and Figueiredo defined M-Learning as a learning with a specific device, at any time and in any place [16]. In 2003 another definition has be provided as a learning mechanism that can take place anytime, anywhere with the help of a mobile computer device. [17].The mobile learning can be defined as a new learning technique using mobile network and tools, expanding digital learning channel, gaining educational services, educational information and educational resources anywhere at any time [18]. Mobile device is a personalized device where it must continuously monitor its environment, thus making mobile applications inherently context aware (collectively location-aware, device-aware, time-aware, etc.) [6], [7]. M-Learning applications are now contextualizing proximity, time, weather, location, etc... to deliver dynamic, hyper-specialized, rich content to learners via context-aware applications. M-Learning using context awareness is new feature and one of the primary factors directing the popularity of M-Learning applications.

\section{M-Learning Is The NeXt Generation of E-Learning}

M-Learning is a technique that uses mobile and wireless technologies for learning and education. M-Learning enables learners to merge their learning experiences in a shared collaborative environment [19]. Currently, Internet and WWW have improved the learning activities providing a high level of interaction between geographically separated teachers and learners. In fact, Internet is not just a way to deliver and distribute the knowledge and learning contents, but it creates learning environments that fit the needs of modern, diverse learners where it engages the learners in many activities such as interactions, collaborations, conversations and problem solving. An Internet enables the e-learning to become the state of art for distance learning over the world and the mobile learning (m-learning) will be the next generation of distance learning. Mobile devices are technologies that can be carried and used everywhere to enable learners accessing knowledge anytime and anywhere. The main target of the next generation of the learning systems is to use current and modern technologies to provide new techniques of learning, training and education that will be easy access and available to all who wish to be part of it. The nomadic computing environment is different from the normal and traditional distributed systems. In nomadic computing environment there is a diversity of , handheld devices, smart phones and mobile workstations, which enable users to access and use Internet services anywhere [20]. Although M-Learning started to be used in supporting a wide range of learning activities there are not much of research done to know the students requirements or understand what types of mobile applications students need to use on their mobile devices and how an effective mobile educational software can be designed to support learning in an educational environments [21]. This rapid increasing of mobile devices in the last 
International Journal of Distributed and Parallel Systems (IJDPS) Vol.3, No.4, July 2012

five years has dramatically altered the platform for business , social, gaming, entertainment, marketing and productivity using software applications. Containing global positioning sensors, wireless connectivity, voice recognition, built-in web browsers, photo/video capabilities among other sensors, mobile devices have enabled the development of mobile applications that can provide rich, highly-localized, context-aware content to users in handheld devices equipped with similar computational power as a standard PC [2]. So far, these novel features present new benefits, challenges and requirements to mobile application developers that are not found in traditional software engineering applications [3].

\section{BENEFIT OF M-LEARNING}

The computing and communication devices such as smart phones, laptops and PDAs with the connection to wireless networks facilitate M-Learning. M-Learning enables educator, learner and teacher to extend beyond the traditional schoolrooms (classroom, tutorial room, laboratories and lecture theatre); The schoolrooms, portable computing and communication devices provide instructors and learners increased flexibility and offer new interaction opportunities. The benefits of M-Learning are as follows:

- Anytime access to content.

- Anywhere access to content.

- Support distance learning.

- Can enhance student-centered learning.

- Great for just-in-time training or review of content.

- It can be used more effectively for the differently-Abled.

- Support differentiation of student learning needs and personalized learning.

- Can enhance interaction between and among students, learners and instructors.

- Reduce cultural and communication barriers between faculty and students by using communication channels that students like.

M-learning is a natural extension of E-learning. It has the potential to additional extend when, where and how students learn and perform in all aspects of their life. One of the main benefits of M-learning is its possibilities to improve students productivity by making knowledge and learning available anytime and anywhere, enabling learners to participate in learning activities without the traditional place and time restrictions. Mobile technologies supports accessible and widely available learning than the learning that used in the existing E-learning environments. M-learning supports performance with easy access to information, which can immediately impact students' performance in a learning environment, facilitating their education. M-learning manages different learning requirements, where it is ideally geared for allowing students to get knowledge at their own speed. M-learning enhances two-way interaction where it supports direct communication between students and their teachers, in such way to encourage shy or hesitant students to communicate more easily than in classrooms. As well as, teachers of large groups can use the direct interaction as a way of giving special instruction to all students. Mlearning also helps students those facing financial, family or health problems in migrating out to university classes. Finally, M-learning is self-motivated, self-disciplined that supports studying with on time waste, studying anywhere and at any time.

\section{Challenges of M-Learning}

The previous benefits, do not come without challenges. The rapid proliferation of mobile applications has outpaced the traditional software applications. However, these traditional software engineering applications cannot be applied directly in mobile devices because of the following issues: 
International Journal of Distributed and Parallel Systems (IJDPS) Vol.3, No.4, July 2012

- Mobile device user interfaces (UI) which provide a new mechanism of human computer interaction sequences such as multi-touch interfaces, image recognition, code scanning, etc... that have not been previously explored in research and there is not any established user interface guidelines exist $[2,4]$.

- Different mobile platforms such as iOS, Android, Windows 7, etc...

- Different hardware makers for platforms such as HTC, Google, Samsung, Apple, etc...

The future challenges of M-learning are as following:

- May make it easier to cheat.

- Finding the best infrastructures.

- Creating universal user interface.

- Design an effective context aware mobile application.

- The problem of learners trusting the wireless network.

- Prevent the disclosing of the learner information via network.

- Could require additional learning curve for non-technical learners.

- Enable the use of M-Learning application across mobile platform.

- Can create a feeling of isolation, separation or of being out-of-the-loop.

- Could give tech-savvy learners an advantage over non-technical learners.

- Might render some content outdated because of rapid upgrades (here today, outdated tomorrow).

\section{Conclusion}

M-Learning makes the merge and connection between technology and education possible. The learner includes nomadic, institutional, home, children and adult users and the variety of learning environments includes standalone, schoolroom, networked, internet-based, nomadic, distance, collaborative, asynchronous and synchronous will arise the interest of the new generation of distance learning (M-learning). The paper has discussed the background of MLearning and how it can be used to enhance the whole learning system. The paper also provides highlights of the benefits and future challenges of M-Learning in our educational environments. Finally, our learners, instructors, students and teachers should be prepared for the next generation of learning and training. The development of a mobile infrastructure for the provision of nomadic learning will meet this need and opening new scenarios for both the developing e-learning and the telecommunication industry. M-learning can be used to solve the traditional learning system problems. Both teachers and students need a proper and handy system to interact with each other and facilitate the teaching system. The M-learning systems are not to replace traditional classrooms but they can be used to complement the learning process in our schools and universities.

\section{ACKNOWLEDGEMENTS}

The authors would like to thank Prof. Hadj Bourdoucen for his valuable comments, constructive criticism, scientific support and guidance. 
International Journal of Distributed and Parallel Systems (IJDPS) Vol.3, No.4, July 2012

\section{REFERENCES}

[1] Gartner Group, "Gartner Says More than 1 Billion PCs In Use Worldwide and Headed to 2 Billion Units by 2014," [Online]. Available: http://www.gartner.com/it/page.jsp?id=703807. [Accessed: 11-Sep-2011].

[2] Oulasvirta, M. Wahlström, and K. Anders Ericsson, "What does it mean to be good at using a mobile device? An investigation of three levels of experience and skill," International Journal of Human-Computer Studies, vol. 69, no. 3, pp. 155-169, Mar. 2011.

[3] I. Wasserman, "Software engineering issues for mobile application development," in Proceedings of the FSE/SDP workshop on Future of software engineering research - FoSER '10, 2010, pp. 397-400.

[4] F. Balagtas-Fernandez, J. Forrai, and H. Hussmann, "Evaluation of user interface design and input methods for applications on mobile touch screen devices," Human-Computer Interaction, pp. 243-246, 2009.

[5] Moodle Corp, 2008. An overview of MOODLE. 20 Nov. 2008. http://moodle.org/about

[6] T. Hofer, W. Schwinger, M. Pichler, G. Leonhartsberger, J. Altmann, and W. Retschitzegger, "Context-awareness on mobile devices - the hydrogen approach," in 36th Annual Hawaii International Conference on System Sciences, 2003. Proceedings of the, 2003.

[7] J. Dey, Anind K., Hakkila, “Context-Awareness and Mobile Devices,” 2008.

[8] N. Jennings, “Agent-oriented software engineering," Multi-Agent System Engineering, pp. 1-7, 1999.

[9] M. Brault, "Disability status and the characteristics of people in group quarters: a brief analysis of disability prevalence among the civilian noninstitutionalized and total populations in the American community survey," US Census Bureau, 2008.

[10] Apple Inc., “iOS Human Interface Guidelines: Introduction." [Online]. Available: http://developer.apple.com/library/ios/\#DOCUMENTATION/UserExperience/Conceptual/Mobil eHIG/Introduction/Introduction.html. [Accessed: 13-Sep-2011].

[11] J. Whittle, P. Sawyer, N. Bencomo, B. H. C. Cheng, and J.-M. Bruel, "RELAX: a language to address uncertainty in self-adaptive systems requirement," Requirements Engineering, vol. 15, no. 2, pp. 177-196, Mar. 2010.

[12] Nadire Cavus \& Dogan Ibrahim, "m-Learning: An experiment in using SMS to support learning new English language words," British Journal of Educational Technology, Volume 40 Issue 1, Pages 78 -91, Feb 2008.

[13] McConatha Douglas, Praul Matt and Lynch Michael J. "Mobile Learning in Higher Education: An Empirical Assessment of a New Educational Tool," Turkish Online Journal of Educational Technology . vol.7,n3 article 2, Jul 2008.

[14] Quinn C. "M-Learning: Mobile , Wireless , In-Your-Pocket Learning," http://www.linezine.com/2.1/features/cqmmwiyp.htm , 2000.

[15] Kristiansen, T. "M-learning. Experiences from the use of WAP as a supplement in learning,"http://www.nadenff.no/nadenff/konferanse/vettre02/TK010430\%20Erfaringsr apport.pdf, 2009.

[16] Chabra T. and Figueiredo J., "How To Design and Deploy And held Learning," http://www.empoweringtechnologies.net/eLearning/eLearning_exPov5_files/frame.htm, 2002.

[17] A Dye, B E Solstad. "J A K Odingo. Mobile Educa-tion-A Glance at The Future," http://www.nettskolen.com/forskning/mobile_education.pdf ,2009.

[18] Yuan Jiugen1, Xing Ruonan2, Wang Jianmin, Applying Research of Mobile Learning Mode in Teaching. International Forum on Information Technology and Applications, 16-18 July 2010. 
International Journal of Distributed and Parallel Systems (IJDPS) Vol.3, No.4, July 2012

[19] Farooq, U, Schafer, W, Rosson, M.B and Caroll, J.M. M-Education: Bridging the Gap of Mobile and Desktop Computing. Centre for Human-Computer Interaction and Department of Computer Science. Virginia Polytechnic Institute and State University, pp. 1-2, 2002.

[20] Giuseppe Laria, Mobile and nomadic user in e-learning: the Akogrimo case, sixth framework programme, Information Society, Fisciano, Italy, 2002.

[21] Devinder Singh \& Zaitun A.B, Mobile Learning In Wireless Classrooms, Malaysian Online Journal of Instructional Technology (MOJIT) Vol. 3, No.2, pp 26-42, August 2006.

[22] Rashmi Padiadpu, Towards Mobile Learning: A SCORM Player for the Google Android Platform Hamburg university of applied science, Master Thesis, Information Engineering, 2008.

[23] Cohen, A. Japan loves wireless. PC Magazine, Vol.21, No.18, p. 136. 2002.

[24] Thornton, P. \& Houser, C. Using Mobile Phones in Education. IEEE International Workshop on Wireless and Mobile Technologies in Education. 2004.

[25] Wains, S. I., \& Mahmood, D. W. Integrating M-Learning with E-Learning. Cincinnati, Ohio, USA. 2008.

[26] Parson D., Ryu H. and Cranshaw M. 2006, "A Study of Design Requirements for Mobile Learning Environments", Proceedings of the sixth International Conference on Advance Learning Technologies.

[27] Sharma S. and Kitchens F. 2004, "Web Service Architecture for MLearning”, Electronic Journal on E-Learning Volume 2 Issue 1.

[28] Barker A., Krull G. and Mallinson B. 2005, "A Proposed Theoretical Model for M-Learning Adoption in Developing Countries", 4th World Conference of M-Learning.

[29] Robert Yu-Liang Ting 2005, "Mobile Learning-Current Trend and Future Challenges", Proceedings of the fifth IEEE ICALT'05.

[30] Saipunidzam Mahamad, Mohammad Noor Ibrahim, Mohamad Izzriq Ab Malek Foad, and Shakirah Mohd Taib. Open Source Implementation of M-Learning for Primary School in Malaysia. International Journal of Human and Social Sciences 3:4 2008

[31] Barkhuus, L. and Dourish, P., 2004. Everyday encounters with context-aware computing in a campus environment. Proceeding of the International Conference on Ubiquitous Computing, Sept. 2004, Springer, Berlin/Heidelberg, pp: 232-249. DOI: 978-3-540- 22955-1

[32] Jihen, M., L. Mona, D. Alain and H.B. Ghezala, 2007. A context aware mobile and collaborative learning scenario. IEEE Multidiscip. Engineering Educ. Mag., 2: 65-69.

[33] Houser, C. and P. Thornton, 2005. Poodle a course management system for mobile phones. Proceedings of the IEEE International Workshop on Wireless and Mobile Technologies in Education, Nov. 2005, IEEE Computer Society, Japan, pp: 211-215. DOI: 10.1109/WMTE.2005.51

\section{Authors}

Dr. Mohamed Sarrab has Ph.D. in Computer Science from De Montfort University 2011. He received his B.Sc. in computer science from 7th April University Libya and also received M.Sc in Computer Science from VSB Technical University of Ostrava Czech Republic. His main research interests are Mobile Applications, M-learning, Computer security, Runtime Verification, Computer forensic.

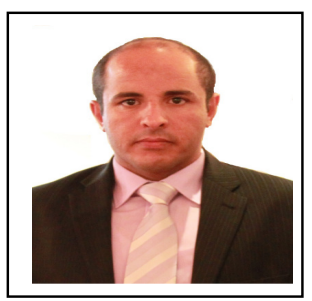


International Journal of Distributed and Parallel Systems (IJDPS) Vol.3, No.4, July 2012

Eng. Laila Elgamel has M.Sc. in Software Engineering from De Montfort University 2011. She received her B.Sc. in computer science from 7th April University Libya a. Her main research interests are Mobile Applications, M-learning, Software Engineering.

Eng. Hamza Aldabbas has M.Sc in computer science from Al-Balqa'a Applied University-Jordan. And B.Sc. in Computer Information System from the same university. His research interests are Human-computer interaction, E-commerce, E-government and M-Learning.

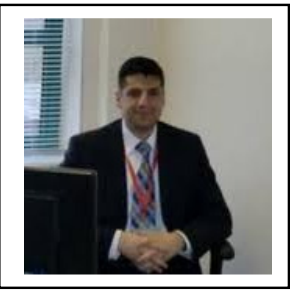

